Demo, David H, and Ritch C. Savin-Williams. (1983). Early adolescent self-esteem as a function of social class: Rosenberg and Pearlin revisited. American Journal of Sociology, 88, 763774.

Made available courtesy of the University of Chicago Press: http://www.press.uchicago.edu

$* * *$ Reprinted with permission. No further reproduction is authorized without written permission from the University of Chicago Press.***

\title{
Early Adolescent Self-Esteem as a Function of Social Class: Rosenberg and Pearlin Revisited ${ }^{1}$
}

\author{
David H. Demo \\ Mississippi State University
}

Ritch C. Savin-Williams

Cornell University

\begin{abstract}
Self-esteem is postulated to be a function of social class in accordance with four theoretical principles-reflected appraisals, self-perception, social comparison, and psychological centrality. It is argued that the ascribed nature of social class among young adolescents makes it a weak determinant of their self-esteem, but that with increasing age socioeconomic position becomes more meaningful and thus more consequential for self-esteem. Data are presented which reveal a stronger association between social class and self-esteem among eighth graders than among fifth graders. One salient characteristic, academic skills, is found to be a strong predictor of early adolescent self-attitudes. Last, levels of self-esteem increase consistently from the fifth to the eighth grade, indicating a developmental trend toward greater self-acceptance.
\end{abstract}

This study is a partial replication and extension of Rosenberg and Pearlin's (1978) article, "Social Class and Self-Esteem among Children and Adults." Their study is important for several reasons. First, the relationship between social class and self-esteem has been largely ignored (Demo 1979), and yet social class is precisely the type of macrostructural variable which Franks and Marolla (1976) deem significant for research aimed at gaining a better understanding of societal effects on self-esteem. Second, Rosenberg and Pearlin provided possible explanations for the contradictions in the sparse literature on the relationship between social class and self-esteem. They utilized four theories-reflected appraisals, social comparison processes, self-perception theory, and psychological centrality-to explain how age functions as a critical intervening variable in the relationship. That is,

1 The first author is grateful for the encouragement and assistance of Joseph Marolla. Neil Henry, Diana Scully, David Franks, Robin Williams, and three anonymous reviewers also contributed by their comments on earlier drafts of this paper. Support for this research was provided by a grant from the National Institute of Education (grant NIE 3-1347). An earlier version of this paper was presented at the Southern Sociological Society Meetings, April 1981, Louisville, Kentucky. Address all communications to David H. Demo, Department of Sociology, P.O. Drawer C, Mississippi State University, Mississippi State, Mississippi 39762.

(C) 1983 by The University of Chicago. All rights reserved. 0002-9602/83/8804-0005\$01.50 
they found that the association between social class and self-esteem is stronger among adults than among children and stronger among older children than among younger ones. Finally, in a review of decades of research in the field of social structure and personality, House (1981) highlighted Rosenberg and Pearlin's contribution, referring to it as the prototypical study of its kind and suggesting that the underlying logic and causal linkages of this research should be extended to other areas of investigation.

In this study, we use three measures of self-esteem rather than one to assess the relationship between social class and self-esteem among young adolescents. Previous studies (Savin-Williams and Jaquish 1981; Demo 1981) have indicated that the Rosenberg Self-Esteem Scale, employed by Rosenberg and Pearlin, does not always correlate highly with other selfesteem measures. Thus, to insure that the relationship between social class and self-esteem found by Rosenberg and Pearlin was not due just to the unique nature of the Rosenberg scale, we thought it best to use other selfesteem scales to test the validity of Rosenberg and Pearlin's findings: the Coopersmith Self-Reported Self-Esteem Instrument, the Marolla LookingGlass Self-Esteem Scale, and the Waetjen-Liddle Learner's Self-Concept Scale. In addition, in this research we address two issues raised but not tested by Rosenberg and Pearlin, issues concerning the effects of two intervening variables-(1) achieved versus ascribed status and (2) homogeneous versus heterogeneous quality of the environment-on early adolescent self-esteem.

Rosenberg and Pearlin's explanation of the conditional relations between social class and self-esteem in three different age brackets-preadolescence (weak association), adolescence (modest association), and adulthood (moderate association) - is based on four theoretical principles. The first principle advanced is that of social comparison processes: children live in a relatively homogeneous world in terms of socioeconomic status, and they view their world accordingly. If they do not perceive themselves as above or below others, but as equals, social class should not affect their selfesteem. To test this, the relationship between social class and self-esteem for students in three schools with a homogeneous social class composition will be compared with the association found among students in four schools that have more heterogeneous social class compositions. According to social comparison processes, the more heterogeneous schools should produce a stronger association.

The second line of reasoning is based on reflected appraisals: if others do not judge children in terms of their SES, then their SES should have little impact on the children's self-esteem. A limitation to Rosenberg and Pearlin's design, however, is their assumption that homogeneity of social class both exists and is perceived as such by individuals in elementary schools. They maintain that students enter more heterogeneous schools only after 
leaving elementary school. This is a serious concern in that, while parents and siblings are indeed of the same social class as the child (Rosenberg and Pearlin 1978, p. 64), thus providing a homogeneous environment, some peers may be of different social classes. Thus, the reflected appraisals of young adolescents may very well be based, at least in part, on social classes. The expectation from the reflected appraisals position is that there will be a weak association between social class and self-esteem among younger adolescents. Since race has been shown to act as a suppressor in this relationship (Rosenberg 1968, 1973; Davis 1971), a separate analysis will control for race. If this relationship is stronger in the heterogeneous schools than in the homogeneous schools, as predicted above, then the evidence will also support the contention that the reflected appraisals of others are incorporating the element of social class.

Self-perception theory provides the third element: children's self-esteem (like that of adults) stems from their own achievements, not from their parents'. This is significant since children's social class is ascribed. A more important and evocative variable to young students is their academic skills. The association between academic skills and self-esteem should thus be stronger than the relationship between social class and self-esteem among early adolescents.

Fourth, psychological centrality predicts that stratification and social class become more understandable and salient with age. That is, to children social class is peripheral and thus unimportant; in contrast, older individuals identify with their socioeconomic position, so it influences their selfesteem. If this is true, social class should become a greater determinant of self-esteem with age. Thus, we test Rosenberg and Pearlin's contention regarding psychological centrality from a developmental perspective. The expectation is a stronger association between social class and self-esteem among older students than among younger ones.

Finally, we examine the relationship between age and self-esteem for our sample of young adolescents. Though not addressed by Rosenberg and Pearlin, this relationship has been thoroughly researched, with no conclusive findings. Wylie's (1979) review of the literature indicates no developmental trend in the absolute level of global self-esteem during the preadolescent and adolescent years. But a recent study by Simmons et al. (1979) found that among students at schools containing kindergarten through eighth grade there was an increase in self-esteem from sixth to seventh grade for both boys and girls; however, girls changing schools to enter seventh grade experienced a decrease in self-esteem. Since all our respondents attended kindergarten-through-eighth-grade schools, it is hypothesized that self-esteem levels will show a developmental pattern of greater self-acceptance with age.

On the basis of these reflections, we propose to replicate the Rosenberg 
and Pearlin study in a somewhat modified form, altering some measures and some questions. Five hypotheses are proposed: (1) The association between father's occupation and student's self-esteem will be weak. (2) There will be a highly positive relationship between student's academic skills and self-esteem. (3) The relationship between father's occupation and student's self-esteem will be stronger among younger adolescents in heterogeneous as opposed to homogeneous schools. (4) The relationship between father's occupation and student's self-esteem will be stronger among eighth graders than among fifth graders. (5) Self-esteem levels will increase consistently from the fifth grade to the eighth grade.

\section{METHOD}

\section{Subjects}

The sample consists of 830 students enrolled in seven midwestern Catholic parochial schools during the 1973-74 school year. They were subjects in a larger research study designed to analyze the effects of open schools on children; two of the schools were open, while the other five followed a traditional format. The schools were located in both inner-city and suburban areas, with three of them enrolling students of lower-class and lowermiddle-class backgrounds and the remaining four drawing from predominantly middle-class families (Franks 1976). Large numbers of both Catholics and Protestants attended the schools.

The subjects were distributed proportionally in the fifth through eighth grades. The sample was $60 \%$ black, $40 \%$ white, $52 \%$ female, and $48 \%$ male. With parental consent, all agreed to participate.

\section{Procedures}

Three self-esteem instruments were administered in classrooms by one researcher, and all were completed within a one-week period. The information on father's occupation, however, was gained through voluntary interviews; this procedure yielded SES data on $74 \%$ of the total sample. ${ }^{2}$

\section{Operationalization of Variables}

Social class.--Social class was operationalized as father's occupation, codified according to U.S. Census Bureau classifications. The validity of this indicator (Blau and Duncan 1967, p. 118) is its correlation with "other status attributes that in their overall configuration amount to a system of social

2 Analysis of the data on those for whom no SES data exist reveals that $53 \%$ had low self-esteem and $47 \%$ had high self-esteem. The percentages for that part of the sample where SES was known were similar: $55 \%$ for low self-esteem and $45 \%$ for high self-esteem. 
stratification." That is, the census classification for occupations is associated with the educational and income levels of the workers. The variable was coded such that children of those employed in professional and management positions were defined as high; children of clerical and sales workers were labeled medium; and the remaining classifications, essentially blue collar (e.g., craftsmen, laborers), were described as low.

Homogeneity and heterogeneity.-An intervening variable, the homogeneity or heterogeneity of the schools in which the early adolescents were enrolled, was also operationalized. Although it was not feasible to measure directly the socioeconomic homogeneity or heterogeneity of the students in the sample being utilized, it was possible to use the distributions of father's occupation in each school. The analysis thus utilized the untested proposition that the objective distribution of father's occupation was closely related to perception of the school environment.

Self-esteem.-The dependent variable, student self-esteem, was measured by the Coopersmith Self-Esteem Inventory, the Marolla Looking-Glass SelfEsteem Scale, and the Waetjen-Liddle Learner's Self-Concept Scale. The instruments were selected to test three theoretical positions: how younger adolescents perceive that others evaluate them, how younger adolescents see themselves, and under what circumstances these self-conceptions vary. Where appropriate, two or more instruments were used to evaluate particular hypotheses.

The Coopersmith instrument is a traditional, widely used scale, thus providing comparability with other studies. Further, Tay'or and Reitz (1968) found a .90 split-half reliability, a .88 test-retest reliability over five weeks, and a .70 test-retest reliability over three years. Robinson and Shaver (1973) report good convergent, discriminant, and predictive validity. This instrument tests each of the five hypotheses.

The Marolla Looking-Glass Self-Esteem Scale determines the relevance of the first hypothesis, that derived from Cooley's theory of reflected appraisals, since it evaluates the ramifications of reflected appraisals on younger adolescents' self-esteem. The instrument has 10 items and a higher internal consistency than the Coopersmith scale.

The Waetjen-Liddle Learner's Self-Concept Scale has been revised specifically for children. A relatively strong correlation (.42) between this instrument and scores on the Iowa Test of Basic Academic Skills reflects the specific focus of this self-concept sca'e: self-esteem in the academic context.

All three self-esteem instruments were moderately correlated in this study. A Pearson correlation of .36 was found between the Coopersmith and Learner scales. Slightly stronger correlations were found between the Marolla instrument and the Learner scale (.38) and between the Marolla scale and the Coopersmith instrument (.44). The unexplained variance indicates that these instruments are imperfect measures of a unitary concept. 


\section{RESULTS}

\section{Hypothesis 1: Social Class and Self-Esteem}

The data on the association between social class and self-esteem supported the first hypothesis. That is, the association between father's occupation and student's self-esteem was weak but positive. As table 1 indicates, gamma associations between father's occupation and the different measures of self-esteem ranged from +.13 to +.20 . When we controlled for race the associations were virtually identical among whites and blacks, though in each case the group reporting the highest self-esteem was composed of whites with high father's occupation. ${ }^{3}$

\section{Hypothesis 2: Academic Skills and Self-Esteem}

The second hypothesis was clearly supported by the data; that is, a clear association existed between student's academic skills and self-esteem. As is evident from table 2, early adolescents' self-esteem increased as their rankings on the Iowa Test of Basic Academic Skills increased (gamma $=+.35)$. Nearly $70 \%$ of those students with low academic ability reported low self-esteem, compared with only $42 \%$ of those with high academic ability.

\section{Hypothesis 3: School Type and Self-Esteem}

No support for the third hypothesis could be generated from the data. Table 3 reveals that the associations between father's occupation and stu-

TABLE 1

SELF-ESTEEM BY FATHER'S OCCUPATION (\%)

\begin{tabular}{|c|c|c|c|}
\hline \multirow[b]{2}{*}{ Self-Esteem } & \multicolumn{3}{|c|}{ FATHER's OCCUPATION } \\
\hline & $\begin{array}{c}\text { High } \\
(N=146)\end{array}$ & $\begin{array}{c}\text { Medium } \\
(N=152)\end{array}$ & $\begin{array}{c}\text { Low } \\
(N=311)\end{array}$ \\
\hline \multicolumn{4}{|l|}{ Coopersmith: } \\
\hline High...... . & 51.4 & 44.7 & 41.8 \\
\hline \multirow{2}{*}{ Low . . . . . . . . } & 48.6 & 55.3 & 58.2 \\
\hline & \multicolumn{3}{|c|}{ Gamma $=+.13 ; \chi^{2}=3.68,2$ df (N.S.) } \\
\hline \multicolumn{4}{|c|}{ 1 log a } \\
\hline High. . & 57.5 & 43.4 & 43.1 \\
\hline \multirow{2}{*}{ Low . . . . . . . . . } & 42.5 & 56.6 & 56.9 \\
\hline & \multicolumn{3}{|c|}{ Gamma $=+.17 ; \chi^{2}=9.17,2 \mathrm{df}(P<.05)$} \\
\hline \multicolumn{4}{|c|}{ 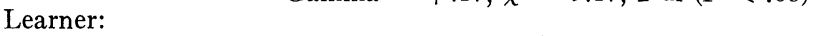 } \\
\hline High. . & 61.0 & 45.4 & 44.1 \\
\hline \multirow[t]{2}{*}{ Low . . . . . . . . } & 39.0 & 54.6 & 55.9 \\
\hline & \multicolumn{3}{|c|}{ Gamma $=+.20 ; \chi^{2}=12.12,2 \mathrm{df}(P<.01)$} \\
\hline
\end{tabular}

3 Since instituting a control for race did not produce significant differences, the corresponding data are not presented here; they are, however, available upon request. 
dent's self-esteem in the homogeneous schools were not significantly different from those in the heterogeneous schools. While the associations in table 3 are actually somewhat stronger in the homogeneous schools, that is due largely to the one high SES school to be discussed below. Once we remove this school from the analysis, table 4 shows a nearly null relationship between social class and self-esteem (gamma $=+.05)$ in the homogeneous schools.

A serendipitous finding that emerged in the evaluation of the third hy-

TABLE 2

SELF-ESTEem By ACADEmic Skills (\%)

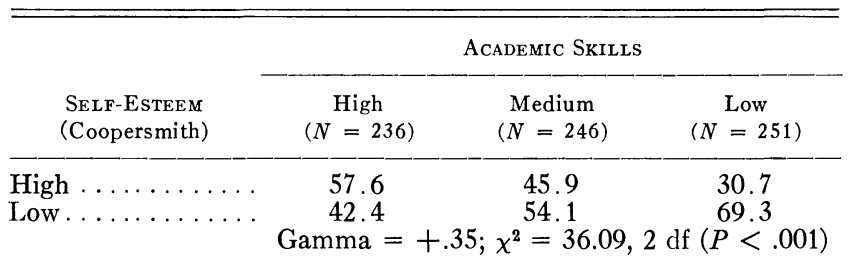

Note.-Student academic abilities measured by Iowa Test of Basic Academic Skills.

TABLE 3

Self-Esteem by Father's Occupation AND By School Environment (\%)

\begin{tabular}{|c|c|c|c|c|c|c|}
\hline \multirow[b]{3}{*}{$\begin{array}{l}\text { SELF-EsTEeM } \\
\text { (Coopersmith) }\end{array}$} & \multicolumn{6}{|c|}{ FATHER'S OCCUPATION } \\
\hline & \multicolumn{3}{|c|}{ Heterogeneous Schools } & \multicolumn{3}{|c|}{ Homogeneous Schools } \\
\hline & $\begin{array}{c}\text { High } \\
(N=54)\end{array}$ & $\begin{array}{l}\text { Medium } \\
(N=82)\end{array}$ & $\begin{array}{c}\text { Low } \\
(N=168)\end{array}$ & $\begin{array}{c}\text { High } \\
(N=92)\end{array}$ & $\begin{array}{l}\text { Medium } \\
(N=70)\end{array}$ & $\begin{array}{c}\text { Low } \\
(N=143)\end{array}$ \\
\hline High. & 51.9 & 42.7 & 43.5 & 511 & 47.1 & 39.9 \\
\hline \multirow[t]{2}{*}{ Low. . . . . . . . } & 48.1 & 57.3 & 56.5 & 48.9 & 52.9 & 60.1 \\
\hline & \multicolumn{3}{|c|}{$\begin{aligned} \text { Gamma } & =+.08 ; \\
\chi^{2} & =1.36,2 \mathrm{df} \text { (N.S.) }\end{aligned}$} & \multicolumn{3}{|c|}{$\begin{aligned} \text { Gamma } & =+.17 ; \\
\chi^{2} & =3.03,2 \mathrm{df} \text { (N.S.) }\end{aligned}$} \\
\hline
\end{tabular}

TABLE 4

Self-EsteEM By Father's OCCUPATION IN HOMOGENEOUS SCHOOLS (\%)

\begin{tabular}{|c|c|c|c|}
\hline \multirow[b]{2}{*}{$\begin{array}{l}\text { Self-Esteem } \\
\text { (Coopersmith) }\end{array}$} & \multicolumn{3}{|c|}{ FATHER'S OCCUPATION } \\
\hline & $\begin{array}{c}\text { High } \\
(N=35)\end{array}$ & $\begin{array}{l}\text { Medium } \\
(N=57)\end{array}$ & $\begin{array}{c}\text { Low } \\
(N=134)\end{array}$ \\
\hline High. & 37.1 & 50.9 & 40.3 \\
\hline Low . . . . . . . & $\begin{array}{c}62.9 \\
\text { Gamma }\end{array}$ & $5 ; \chi^{2}=2$ & $\begin{array}{c}59.7 \\
\text { df (N.S.) }\end{array}$ \\
\hline
\end{tabular}

NoTE.-This set of homogeneous schools excludes those students in school 5, as discussed in the text. The excluded children are represented in table 5. 
pothesis was that in one of the seven schools (school 5 shown in table 5) the data revealed a strong association (gamma $=+.48$ ) between father's occupation and student's self-esteem. In the other schools no more than a weak association (gamma $=+.21$ ) was found. In school 5 nearly $60 \%$ of those children whose father's occupation was in the highest category had high self-esteem, while among those whose father's occupation was classified as middle and low, only $31 \%$ and $33 \%$, respectively, possessed high selfesteem. This particular school is predominantly female, and the social class composition is skewed toward the higher end relative to the other six schools constituting the sample. Perhaps in this setting the students were more aware of socioeconomic status and thus more apt to make invidious comparisons on the basis of social class, thereby making social class a greater determinant of self-esteem.

\section{Hypothesis 4: Social Class and Self-Esteem by Grade}

The data supported the expectation that social class should have a greater effect on the self-esteem of eighth graders than on that of fifth graders. The associations between father's occupation and the different measures of student's self-esteem were nearly null among fifth graders (gamma = -.08 and +.03$)$, but moderate among eighth graders $($ gamma $=+.28$ and +.37 ) (table 6).

The mean self-esteem levels of both the fifth graders and the eighth graders are shown in table 7 . Across all three occupational categories the Coopersmith scores dropped and the Learner scores increased, both indicating higher self-esteem among eighth graders than among fifth graders. This had been expected in the highest occupational group but was the reverse of what had been hypothesized for the lowest category.

The increase in self-esteem, however, was greater among those in higher social classes than for the lowest occupational group. Upon further exam-

TABLE 5

Percentage Having High Self-Esteem by Father's

OCCUPATION AND BY SCHOOL

\begin{tabular}{|c|c|c|c|c|c|}
\hline \multirow[b]{2}{*}{ SсHоOL } & \multicolumn{3}{|c|}{ Father's OCCUPATION } & \multirow[b]{2}{*}{ Gamma } & \multirow[b]{2}{*}{$P$} \\
\hline & High & Medium & Low & & \\
\hline 1. & $45.5(11)$ & $68.8(16)$ & $51.2(41)$ & +.07 & .396 \\
\hline 2. & $66.7(6)$ & $31.3(16)$ & $38.9(36)$ & +.11 & .315 \\
\hline & $50.0(12)$ & $34.6(26)$ & $50.0(36)$ & -.11 & 446 \\
\hline 4 . & 43.8 (16) & $52.4(21)$ & $37.8(45)$ & +.15 & .533 \\
\hline 5. & $59.6(57)$ & 30.8 (13) & $33.3(9)$ & $\begin{array}{r}+.48 \\
+.48\end{array}$ & .085 \\
\hline$\ldots \ldots$ & $31.6(19)$ & $50.0(36)$ & $41.6(89)$ & -.01 & 409 \\
\hline 7. & $520(25)$ & $41.7(24)$ & $36.4(55)$ & +.21 & .420 \\
\hline
\end{tabular}

Note.-Self-esteem was measured using the Coopersmith instrument. $N$ 's are in parentheses. 
ination an analysis of variance revealed that age was a significant variable in determining self-esteem $(P<.01)$ but father's occupation was not. However, the interaction effects of age and father's occupation were significant $(P<.05)$. Self-esteem thus reflected social class more among the eighth graders than among the fifth graders.

\section{Hypothesis 5: Age and Self-Esteem}

As indicated by the analysis of variance reported above, age was a significant variable in determining self-esteem $(P<.01)$. Further examination

TABLE 6

SELF-ESTEEM BY FATHER'S OCCUPATION AND BY GRAdE

\begin{tabular}{|c|c|c|c|c|c|c|}
\hline \multirow[b]{3}{*}{ Self-Esteem } & \multicolumn{6}{|c|}{ FATHER's OCCUPATION } \\
\hline & \multicolumn{3}{|c|}{ Fifth Graders } & \multicolumn{3}{|c|}{ Eighth Graders } \\
\hline & High & Medium & Low & High & Medium & Low \\
\hline \multicolumn{7}{|l|}{ Coopersmith:* } \\
\hline High $(\%)$ & 286 & 24.2 & 30.4 & 65.5 & 61.9 & 47.0 \\
\hline Low $(\%)$ & 71.4 & 75.8 & 69.6 & 34.5 & 38.1 & 53.0 \\
\hline$N \ldots \ldots$ & 21 & 33 & 69 & 55 & 42 & 83 \\
\hline \multicolumn{7}{|l|}{ Learner:† } \\
\hline High $(\%)$.. & 47.6 & 24.2 & 36.2 & 65.5 & 71.4 & 42.2 \\
\hline Low $(\%)$. & 52.4 & 75.8 & 63.8 & 34.5 & 28.6 & 57.8 \\
\hline$N \ldots \ldots$ & 21 & 33 & 69 & 55 & 42 & 83 \\
\hline
\end{tabular}

* Grade 5, gamma $=+.08, \chi^{2}=.42,2 \mathrm{df}$ (N.S.); grade 6, gamma $=+.34, \chi^{2}=6.11,2 \mathrm{df}(P<.05)$; grade 7 , gamma $=-.21, \chi^{2}=2.69,2 \mathrm{df}$ (N.S.); grade 8, gamma $=+.28, \chi^{2}=5.33,2 \mathrm{df}(P<.10)$.

$\dagger$ Grade 5, gamma $=+.03, \chi^{2}=3.20,2 \mathrm{df}$ (N.S.), grade 6, gamma $=+.10, \chi^{2}=6.17,2 \mathrm{df}(P<.05)$; grade 7 , gamma $=+.12, \chi^{2}=1.97,2 \mathrm{df}$ (N.S.); grade 8, gamma $=+.37, \chi^{2}=12.50,2 \mathrm{df}(P<.01)$.

TABLE 7

MEAN SELF-ESTEEM LEVELS By FATHER'S OCCUPATION AND BY AGE

\begin{tabular}{|c|c|c|}
\hline $\begin{array}{l}\text { Father's } \\
\text { Occupation }\end{array}$ & $\begin{array}{c}\text { Fifth } \\
\text { Graders }\end{array}$ & $\begin{array}{l}\text { Eighth } \\
\text { Graders }\end{array}$ \\
\hline & \multicolumn{2}{|c|}{ Coopersmith Scores } \\
\hline High. & 33.80 & 30.45 \\
\hline Medium. & 33.62 & 30.93 \\
\hline \multirow[t]{2}{*}{ Low . . . . . . . . . . } & 3330 & 31.55 \\
\hline & \multicolumn{2}{|c|}{ Learner Scores } \\
\hline High. . . . . . . . & 51.18 & 52.76 \\
\hline Medium .......... & 48.21 & 52.57 \\
\hline Low . . . . . . . . . & 49.95 & 50.11 \\
\hline
\end{tabular}

NoTE.-According to analysis of variance, main effect of father's occupation, $P>.10$; main ef fect of age, $P<.01$; interaction effects of father's occupation and age, $P<.05$. 
reveals clear support for the expectation of a developmental trend toward greater self-esteem. Both the Coopersmith and Learner instruments show an increase in self-esteem with each grade (tables 7 and 8). Among fifth graders the two instruments report $25 \%$ and $30 \%$, respectively, as having high self-esteem, while among eighth graders both scales report over $50 \%$ as having high self-esteem (table 8).

\section{DISCUSSION}

Four of the five hypotheses proposed in this paper were supported by the data. The relationship between social class and self-esteem among younger adolescents projected in hypothesis 1 was somewhat stronger than had been expected but was still consistent with the earlier findings of Rosenberg and Pearlin (1978). It appears, then, that a social structural variable, social class, contributes to self-conceptions even during the early adolescent years. In an effort to understand better how these processes operate, four additional hypotheses were examined.

A relatively strong association was found between academic skills and self-esteem. This supports self-perception theory and suggests that personal abilities and accomplishments play a significant role in determining feelings of self-worth.

The hypothesis that a stronger association between social class and selfesteem exists in heterogeneous schools than in homogeneous environments was not supported by the data. Although it is possible that social comparison processes were not functioning as had been theorized, methodological limitations in the analysis of this hypothesis must also be recognized. The indicator of homogeneity used in this research was distribution of father's occupation in the different schools comprising the sample. Perhaps the distinction drawn between homogeneous and heterogeneous schools was not

TABLE 8

Self-Esteem Levels by Age

\begin{tabular}{|c|c|c|c|c|}
\hline Self-Esteem & $\begin{array}{l}\text { Fifth } \\
\text { Graders }\end{array}$ & $\begin{array}{l}\text { Sixth } \\
\text { Graders }\end{array}$ & $\begin{array}{l}\text { Seventh } \\
\text { Graders }\end{array}$ & $\begin{array}{l}\text { Eighth } \\
\text { Graders }\end{array}$ \\
\hline \multicolumn{5}{|l|}{ Coopersmith: } \\
\hline High $(\%)$ & 24.8 & 39.7 & 50.8 & 57.9 \\
\hline Low (\%). & 752 & 60.3 & 49.2 & 42.1 \\
\hline$N \ldots \ldots$ & 157 & 180 & 232 & 239 \\
\hline Mean......... & 33.75 & 32.67 & 31.67 & 31.14 \\
\hline \multicolumn{5}{|l|}{ Learner: } \\
\hline High $(\%)$. & 304 & 46.7 & 49.6 & 50.6 \\
\hline Low $(\%)$ & 696 & 53.3 & 50.4 & 49.4 \\
\hline$N \ldots \ldots$ & 154 & 174 & 229 & 229 \\
\hline Mean & 49.09 & 50.69 & 51.63 & 51.32 \\
\hline
\end{tabular}


sufficient to produce different associations, particularly since the strongest association was found in a "homogeneous" school. This unexpected finding suggests, however, that socioeconomic status was important to these younger adolescents. This is consistent with the psychological centrality argument.

The data supported the expectations that social class would be a greater determinant of self-esteem among eighth graders than fifth graders and that self-esteem levels would increase with age. Congruent with the psychological centrality argument, older students should be more aware of social class differences, which are thus implied to have increased importance for them. Further research should follow the investigation of these trends into later adolescence and adulthood.

Finally, this research suggests that it is necessary to examine the effects of social class on self-esteem within a longitudinal framework. In the present research different populations were utilized for each grade. While a cohort analysis is useful, a longitudinal analysis would control for the possibility that one population had higher self-esteem than another population and provide useful data on the effect of social change within a family on early adolescent self-esteem. Such an analysis is currently in progress; it extends the present examination to a modified longitudinal sample of seventh through tenth graders. Certainly further research is necessary in order to understand the complex nature of the intervening variables in the relationship between social class and self-esteem.

\section{REFERENCES}

Blau, Peter M., and Otis D. Duncan. 1967. The American Occupational Structure. New York: Wiley.

Davis, James A. 1971. Elementary Survey Analysis. Englewood Cliffs, N.J.: PrenticeHall.

Demo, David H. 1979. "Social Class and Self-Esteem among Preadolescents." M.A. thesis, Virginia Commonwealth University.

1981. "Theoretical and Methodological Considerations in the Study of SelfEsteem." Ph.D. dissertation, Cornell University.

Franks, David D. 1976. "The Effects of Open Schools on Children: An Evaluation." National Institute of Education, Project no. 3-1347. University of Denver.

Franks, David D., and Joseph A. Marolla. 1976. "Efficacious Action and Social Approval as Interacting Dimensions of Self-Esteem: A Tentative Formulation through Construct Validation." Sociometry 39:324-41.

House, James S. 1981. "Social Structure and Personality." Pp. 525-61 in Social Psychology: Sociological Perspectives, edited by Morris Rosenberg and Ralph H. Turner. New York: Basic.

Robinson, J., and P. Shaver. 1973. Measures of Social Psychological Attitudes. Ann Arbor, Mich.: Institute for Social Research.

Rosenberg, Morris. 1968. The Logic of Survey Analysis. New York: Basic.

$37: 359-72$. 


\section{American Journal of Sociology}

Rosenberg, Morris, and Leonard I. Pearlin. 1978. "Social Class and Self-Esteem among Children and Adults." American Journal of Sociology 84:53-77.

Savin-Williams, Ritch C., and Gail A. Jaquish. 1981. "The Assessment of Adolescent Self-Esteem: A Comparison of Methods." Journal of Personality 49:324-36.

Simmons, Roberta G., Dale A. Blyth, Edward F. VanCleave, and Diane Mitsch Bush. 1979. "Entry into Early Adolescence: The Impact of School Structure, Puberty, and Early Dating on Self-Esteem." American Sociological Review 44:948-67.

Taylor, J., and W. Reitz. 1968. "The Three Faces of Self-Esteem." Research Bulletin 80. Department of Psychology, University of Western Ontario.

Wylie, Ruth C. 1979. The Self-Concept. Vol. 2. Rev. ed. Lincoln: University of Nebraska Press. 